\title{
O MÉTODO HIPOTÉTICO DEDUTIVO NO ENSINO FUNDAMENTAL: UMA PROPOSTA PRÁTICA PARA O ENSINO DE CIÊNCIAS NATURAIS NO TEMA TRANSPIRAÇÃO DAS PLANTAS.
}

Débora Regina Soares de Oliveira ${ }^{a}$ Gelcimara de Lima Nobre ${ }^{b}$ Lúcia Helena Soares de Oliveira ${ }^{\mathrm{c}}$ Cirlande Cabral da Silva ${ }^{\mathrm{d}}$

\section{A R T I C L E I N F O}

\author{
Palavras chave: \\ Método Hipotético Dedutivo; \\ Ensino de Ciências; \\ Prática docente; \\ E-mail: \\ a deborarsdo@gmail.com \\ b gelcimara_nobre@hotmail.com \\ c oliveiralucia63@hotmail.com \\ d cirlandecabral@gmail.com
}

\section{R E S U M O}

O presente trabalho apresenta uma aula experimental desenvolvida na disciplina Instrumentação para o Ensino de Ciências, ministrada no Mestrado em Ensino de Ciências na Amazônia/UEA. Este trabalho objetivou destacar que o Método Hipotético Dedutivo (MHD) é uma ferramenta muito útil no ensino no campo das ciências ambientais, já que ele permite desfazer ideias incorretas acerca dos fenômenos observados ou questionados. De acordo com o MHD toda investigação então nasce de algum problema prático/teórico sentido. É ele que dirá o que é relevante ou irrelevante pesquisar e quais os dados que devem ser selecionados. Esta seleção exige então uma hipótese, que são a conjectura e/ou suposição, que servirá de guia ao pesquisador. A metodologia utilizada foi uma Sequencia Didática com a utilização de experimentação com materiais manipuláveis. A investigação teve como premissa o seguinte questionamento: É possível utilizar este método de pesquisa no ensino de Ciências Naturais no Ensino Fundamental? Portanto, apesar de o método hipotéticodedutivo ser pouco utilizado em práticas educacionais no Ensino de Ciências, o resultado encontrado nessa aula experimental demonstrou que a possibilidade de adaptar experimentos em geral para este método é valido, no entanto, é importante que o docente tenha uma boa compreensão do método para que possa dirimir as possíveis dúvidas e nesse processo o aluno também tenha suas hipóteses elucidadas de acordo com o conhecimento científico.

\section{INTRODUÇÃO}

Este artigo é resultado do trabalho final da disciplina Instrumentação para o Ensino de Ciências, ministrada no Mestrado em Ensino de Ciências na Amazônia. No decorrer da disciplina nos foi proposto elaborar uma aula utilizando o Método Hipotético 


\section{REVISTA REAMEC}

Revista ta Rede Amazorinica de Edurecrăo

em Ciêneias e Matemática
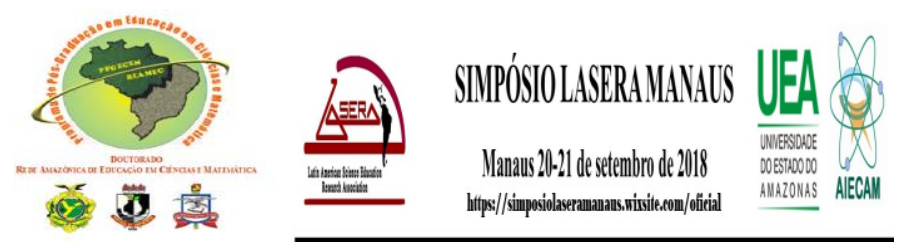

Dedutivo (MHD) para o Ensino Fundamental abordando os conteúdos de Ciências Naturais. Objetivou-se elaborar uma sequencia didática do conteúdo curricular: Respiração das Plantas, utilizando o MHD e aplicá-lo na turma do mestrado que estava fazendo a disciplina de Instrumentação. $\mathrm{O}$ texto se divide em Referencial Teórico, onde são apontados os conceitos básicos sobre o MHD, a metodologia adotada e os resultados alcançados com as discussões suscitadas na aula de experimentação.

Portanto, para que ocorra a aplicação do Método Hipotético Dedutivo (MHD) na aula de experimentação é necessário desenvolver um planejamento organizado, visto que, a vantagem da utilização do método está exatamente na possibilidade de eliminação de hipóteses equivocadas, onde o professor media o processo de maneira que os estudantes compreendam e apreendam corretamente os conceitos científicos.

\section{A questão do método}

Muito além das relações entre objeto e sujeito presentes no conhecimento científico, existe também uma enorme discussão sobre a função do método na construção do conhecimento. O Método seria o conjunto de normas que possibilitariam a mediação entre a realidade concreta e a teoria. Para Bunge:

Método é um procedimento regular, explícito e passível de ser repetido para conseguir algo material ou conceitual. Método científico é um conjunto de procedimentos por meio dos quais são propostos os problemas científicos e, a seguir, são colocadas à prova as hipóteses científicas (BUNGE, 1974, p.72).

Nesta perspectiva, o método representa uma técnica que pode levar o pesquisador a um determinado resultado na elaboração do conhecimento científico. Sobre o Método Científico Popper afirma “... eu tenho tentado desenvolver a tese de que o método científico consiste na escolha de problemas interessantes e na crítica de nossas permanentes tentativas experimentais e provisórias de solucioná-los" (POPPER, 1975, p. 14).

O Método Científico é então, uma organização de etapas pelas quais se descobrem novas relações entre os fenômenos que interessam a um determinado campo científico ou aspectos ainda não revelados de um determinado fenômeno. É através do método que novas 


\section{REVISTA REAMEC}

Revista ta Rede Amazorinica de Edurecrăo

em Ciêneias e Matemática
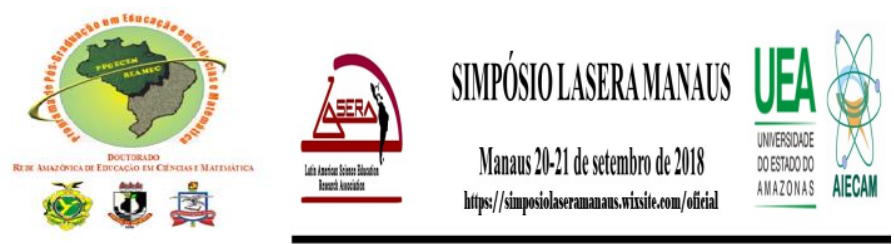

conclusões são incorporadas, sistematizando as atividades de investigação com o novo conhecimento paralelamente.

Alguns pensadores contribuíram para a consolidação do Método da maneira que se investiga nos dias atuais (CONAN, 1987), Galileu (1564-1642) foi o precursor teórico do método experimental, quando contradizendo os ensinamentos de Aristóteles, preconizou que o conhecimento íntimo das coisas deveria ser substituído pelo conhecimento de leis gerais que condicionam as ocorrências. Sugeriu iniciar a investigação do particular para o geral (Indução) com base na experimentação (Indução Experimental). Assim também, Francis Bacon (1561-1626) contemporâneo de Galileu, destacou serem essenciais a observação e a experimentação dos fenômenos reiterando que a verdade de uma afirmação só poderá ser proporcionada pela experimentação, ele desenvolveu então o Método das coincidências constantes.

Por outro lado, Descartes (1596-1650) propôs um processo que se afasta em essência do pensamento anterior, pois em vez de usar inferência indutiva, utiliza-se a inferência dedutiva, ou seja, o conhecimento partindo do geral para o particular. A certeza somente poderá ser alcançada pela razão.

Na continuidade da evolução do pensamento, Kall Popper (1975) propõe o Método Hipotético-Dedutivo, que é um método que procura uma solução, por meio de tentativas (conjecturas, hipóteses, teorias) e eliminação de erros. Esse método pode também ser chamado de "método de tentativas e eliminação de erros".

O método hipotético-dedutivo surgiu na ciência através das críticas do autor Sir Karl Raymund Popper sobre as discussões que havia entre os métodos indutivos versus dedutivos. Segundo Popper (1975), a ciência é hipotética e provisória, e não um conhecimento definitivo.

Um ponto fundamental no Método Hipotético Dedutivo é o Problema, toda pesquisa tem origem num problema para o qual se procura uma solução, através de tentativas, conjecturas, hipóteses, teorias e eliminação de erros. Popper em sua obra Conjecturas $e$ refutações afirma:

Meu ponto de vista é de (...) que a ciência parte de problemas; que esses problemas aparecem nas tentativas que fazemos para compreender o mundo da nossa 'experiência' ('experiência' que consiste em grande parte de expectativas ou teorias, e também em parte em conhecimento derivado da observação - embora ache que 


\title{
REVISTA REAMEC
}

Revista ta Rete Amazonitiea de Edureçăo
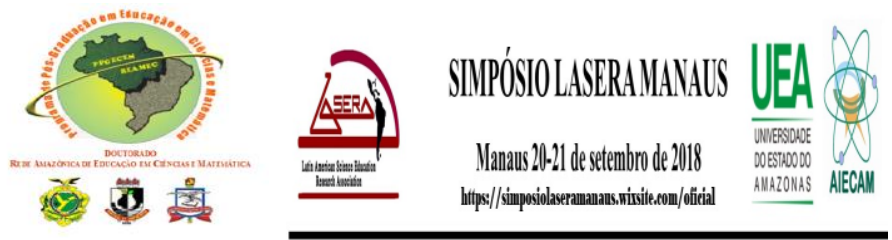

não existe conhecimento derivado da observação pura, sem mescla de teorias e expectativas) (POPPER s.d.:181).

Conforme Lakatos e Marconi (2003):

\begin{abstract}
A primeira etapa do método proposto por Popper é o surgimento do problema. Nosso conhecimento consiste no conjunto de expectativas que formam como que uma moldura. A quebra desta provoca uma dificuldade: o problema que vai desencadear a pesquisa. Toda investigação nasce de algum problema teórico/prático sentido. Este dirá o que é relevante ou irrelevante observar, os dados que devem ser selecionados. Esta seleção exige uma hipótese, conjectura e/ou suposição, que servirá de guia ao pesquisador. (LAKATOS \& MARCONI 2003, p. 97).
\end{abstract}

De acordo com o MHD toda investigação então nasce de algum problema prático/teórico sentido. É ele que dirá o que é relevante ou irrelevante pesquisar e quais os dados que devem ser selecionados. Esta seleção exige então uma hipótese, que é a conjectura e/ou suposição, que servirá de guia ao pesquisador. Nesta perspectiva, o ponto crucial no MHD são as Hipóteses ou Conjecturas. Elas têm dois papeis na investigação: propor explicações dos problemas abordados e também guiar a tomada de dados, elas se aperfeiçoam quando se tornam mais simples, quantitativas e gerais. Para Lakatos e Marconi (2003),

Se a hipótese não supera os testes, está falseada, refutada, e exige nova reformulação do problema e da hipótese, que, se superar os testes rigorosos, está corroborada, confirmada provisoriamente, não definitivamente como querem os indutivistas (LAKATOS \& MARCONI 2003, p. 98).

Nesse entendimento, hipótese é diferente de problema e diferente de objetivos, podendo ser definida como um enunciado de relacionamento entre variáveis, uma relação de causa e efeito objeto da verificação empírica (experimentação ou observação naturalista), ou seja, uma resposta provisória. A Hipótese precisa ter coerência lógica e suporte teórico (atualização e experiência), ser uma proposição testável, explicação ou solução provisória para o problema; necessita ter clareza e simplicidade e estar relacionada a técnicas disponíveis, além de ser simples e clara. Einstein afirmou, "O sábio entre várias hipóteses, escolhe sempre a que lhe parece menos complexa", verossímil, pertinente e verificável experimentalmente (PONTES, 1998 apud LAKATOS \& MARCONI 2003). 


\section{REVISTA REAMEC}

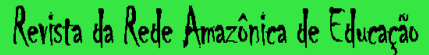

em Ciêneias e Matemática

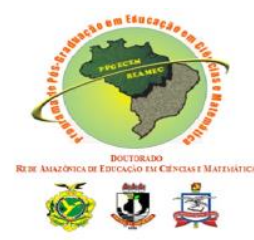

O terceiro momento do processo investigatório é o chamado de Falseamento, de acordo com Marconi e Lakatos (2003),

Nesta terceira etapa do método hipotético-dedutivo, realizam-se os testes que consistem em tentativas de falseamento, de eliminação de erros. Um dos meios de teste, que não é o único, é a observação e experimentação. Consiste em falsear, isto é, em tornar falsas as conseqüências deduzidas ou deriváveis da hipótese. Quanto mais falseável for uma conjectura, mais científica será, e será mais falseável quanto mais informativa e maior conteúdo empírico tiver (LAKATOS \& MARCONI 2003, p. 98).

Por fim, Popper afirma que "É verificando a falsidade de nossas suposições que de fato estamos em contato com a realidade" (POPPER, 1975b, p. 331). Caso a hipótese não seja comprovada pelos testes, ela estará superada, ou seja, será falseada. Sendo assim, será preciso uma nova reformulação do problema e da hipótese. Caso os testes e experiências confirmem a hipótese, ela estará corroborada, quer dizer, corroborada provisoriamente, já que ela poderá ser superada em um eventual outro estudo.

\section{METODOLOGIA}

A metodologia utilizada foi experimental com base no Método Hipotético Dedutivo. Podemos destacar que o método (MHD) é uma ferramenta muito útil no ensino no campo das ciências ambientais, já que ele permite desfazer ideias incorretas acerca dos fenômenos observados, como por exemplo, o funcionamento da natureza. As etapas compreenderam: a) Colocação do problema: reconhecimento dos fatos; descoberta do problema e formulação do problema, b) Construção de um modelo teórico: seleção dos fatores pertinentes e invenção das hipóteses centrais e das suposições auxiliares, c) Teste das hipóteses, d) Adição ou introdução das conclusões na teoria: comparação das conclusões com as predições e retrodições; reajuste do modelo e sugestões para trabalhos posteriores. Como resultado, as ideias incorretas foram eliminadas, e a ideia que resultou do processo de descarte foi considerada provisoriamente "verdadeira" (Poper, 1975).

\section{RESULTADOS E DISCUSSÃO}

\subsection{O método hipotético dedutivo no ensino de ciências naturais}




\section{REVISTA REAMEC}

Revista ta Rede Amazorinica de Edurecrăo

em Ciêneias e Matemática
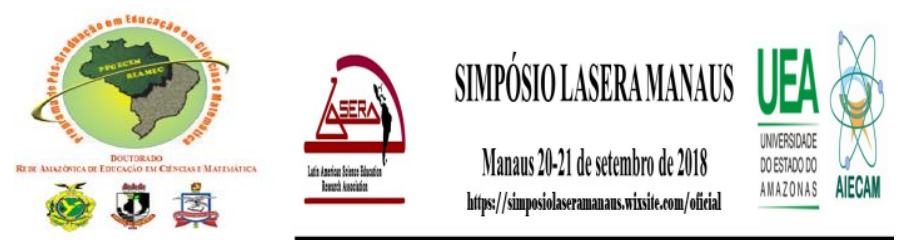

No desenvolvimento da experimentação foram pontuados alguns conceitos básicos sobre o MHD partindo do seguinte questionamento: É possível utilizar este método de pesquisa no ensino de Ciências Naturais no Ensino Fundamental? Essa foi a questão inicial suscitada para a utilização do Método na aula experimental.

Segundo o Parâmetro Curricular Nacional de Ciências Naturais do Ensino Fundamental (BRASIL, 1998) deve-se pensar um ensino onde o aluno possa vivenciar observações, levantar hipóteses, testá-las, refutá-las e abandoná-las quando for o caso, trabalhando de forma a redescobrir conhecimentos. Porém, quando esse entendimento não faz parte do pensamento da escola à aprendizagem fica comprometida. E embora ocorra toda essa fundamentação para uma aprendizagem que valorize as potencialidades do sujeito, a escola ainda continua na prática da acumulação de informações e em contextos poucos significativos para o aluno (BRASIL, 1998, p.04).

Nesta dimensão, entende-se que o educador é o responsável em buscar instrumentos que possibilitem uma aprendizagem contextualizada com a vivência do aluno. O processo educativo depende na sua plenitude do ato de aprender. Contudo, é importante que para que esse aprender aconteça, seja necessário o uso de estratégias e recursos que estimulem o entendimento lógico-abstrato. Perceber essa necessidade no processo educativo pode ser um referencial necessário na questão do aprendizado de conceitos. Entendendo que a ciência faz parte do cotidiano do aluno e que o mesmo precisa não só questionar, mas valorizar o meio onde vive (CHASSOT, 2000).

Pensando nessa possibilidade, na disciplina Instrumentalização para o Ensino de Ciências, ministrada pelo Programa de Pós-graduação em Educação e Ensino de Ciências na Amazônia, um dos desafios proposto pelo Professor da disciplina foi desenvolver uma aula com a turma. Nessa aula deveria utilizar o método hipotético-dedutivo como metodologia de ensino.

No aprofundamento dos estudos sobre o método (MHD) percebemos que este método não é comumente utilizado em sala de aula no ensino fundamental, porém não significa que seja impossível o docente utilizá-lo em suas práticas, no entanto, entende-se que este processo exige pesquisa e compreensão do método para então planejar e adaptar a metodologia ao conteúdo curricular planejado. 


\section{REVISTA REAMEC}

Revista ta Rede Amazoritica de Edurecrăo

em Ciêneias e Matemática
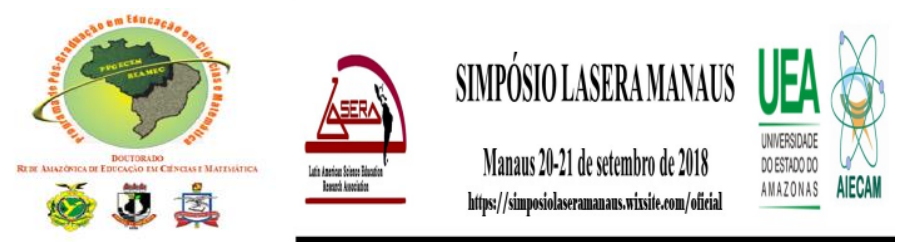

3.2 Aplicação do MHD em uma aula de ciências sobre o tema Transpiração das

\section{Plantas}

$\mathrm{Na}$ continuidade do processo aplicamos o método em uma aula sobre o tema "A transpiração das plantas". Inicialmente elaboramos um roteiro utilizando o método hipotéticodedutivo considerando o problema como ponto de partida para essa prática. Baseado no problema levantado que foi : "Por que é importante que os estudantes conheçam o processo de transpiração das plantas no Ensino de Ciências? A partir dessa problematização as lacunas ou contradições foram formuladas e as conjecturas, soluções ou hipóteses foram apontadas como discussão inicial na aula.

Partindo dessa questão com os estudantes surgiu a seguinte hipótese sobre o assunto: "A transpiração dos vegetais é um processo que ocorre quando a planta absorve água". Salientou-se que a hipótese no método hipotético-dedutivo deve sempre ser uma afirmação, que por sua vez, são testadas no que Popper (1975) chamou de técnica de falseamento. É importante entender que na prática docente é importante ouvirmos o que os estudantes sabem sobre o tema abordado, pois é comum que alguns estudantes do ensino fundamental tenham algum conhecimento prévio sobre o assunto, como neste caso, acerca da transpiração das plantas.

Com a hipótese formulada, foi possível então pensarmos no objetivo do experimento que consistiu em investigar a transpiração de uma folha de vegetal. Antes de iniciarmos o experimento, com o diagnóstico prévio um dos estudantes afirmou que "já viram uma planta suando através de gotinhas de água nas folhas" (Estudante 1).

Após o primeiro momento os estudantes com o roteiro elaborado em mãos, foram convidados a se organizarem ao redor de uma mesa que continha os seguintes materiais: Copos de vidro; Copos de plástico; Pote de vidro; Saco plástico; Pedaço quadrado de papel cartão com furo no meio (previamente elaborado pelo docente por medida de segurança); Jarra com água; Folha com pecíolo ("haste”) firme; Pedaço de galho com folhas e Massa de modelar;

A partir deste momento, os estudantes organizados em duplas iniciaram os procedimentos do experimento. Vale ressaltar, que um dos princípios do MHD é o relacionamento entre variáveis, desta forma foram formulados três tipos de experimentos para 
REVISTA REAMEC

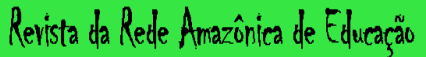
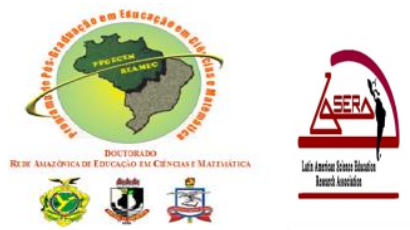

SIMPÓSOLASERAMAVALS

em Ciências e Matemática

comparação: Um experimento com copos de vidro, um experimento com copos de plástico e um experimento com um pote de vidro e sacola plástica.

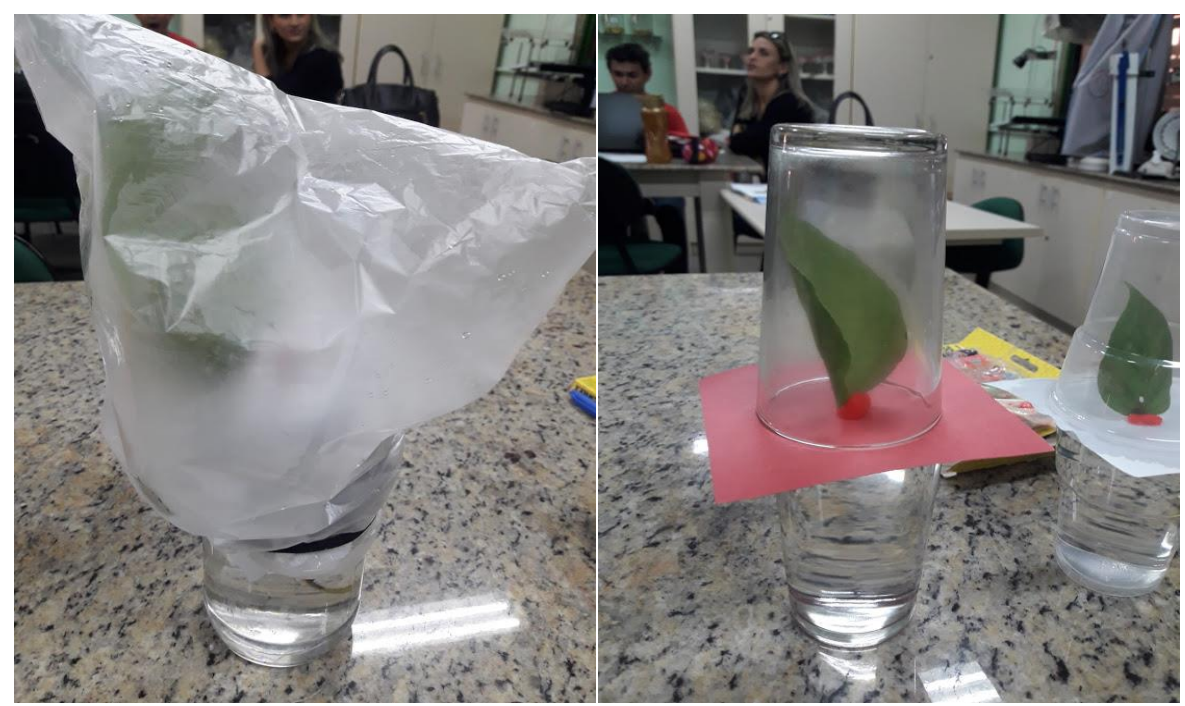

Figura 1: experimentos realizados pelos estudantes

Fonte: Autores

Para os experimentos com os Copos de vidro e de plástico os procedimentos foram os seguintes:

Procedimento 1: Foi solicitado que os estudantes empurrassem o pecíolo da folha, através do furo no pedaço de papel cartão (cerca de $4 \mathrm{~cm}$ abaixo do cartão, evitando encostar a folha no cartão).

Procedimento 2: Em seguida, pegue a massa de modelar e pressione contra o cartão em volta do pecíolo (Figura B).

Procedimento 3: Encha os copos com água e posicione o cartão com a folha no topo do copo, de modo que o pecíolo fique mergulhado na água (Figura $\mathrm{C}$ ).

Procedimento 4: Coloque o copo vazio sobre o cartão, de modo a cobrir a folha (Figura D).

Procedimento 5: Deixe os experimentos sob iluminação natural por algum tempo. 


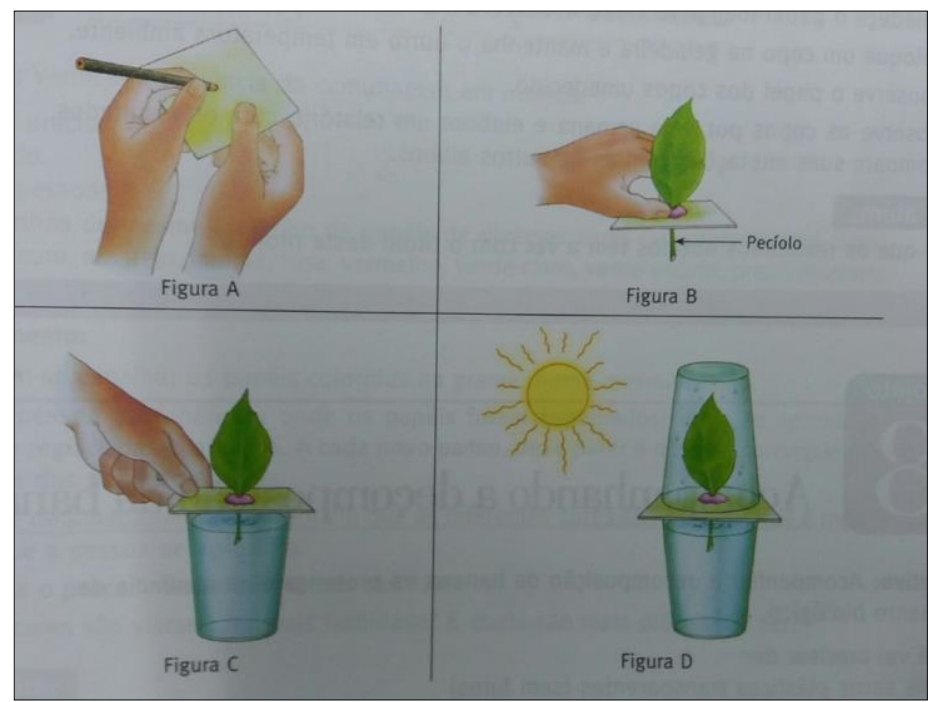

Figura 2: Ilustração das etapas do experimento

Fonte: Livro Ciências Naturais $6^{\circ}$ ano

Para os experimentos com o pote de vidro e a sacola plástica os procedimentos foram os seguintes:

Procedimento 1: Foi solicitado que os estudantes empurrassem o pedaço de galho com folhas através do furo no pedaço de papel (evitando encostar a folha no cartão).

Procedimento 2: Em seguida, pegue a massa de modelar e pressione contra o cartão em volta do galho (Figura B).

Procedimento 3: Encha o pote de vidro com água, coloque o galho da planta e feche o vidro com o saco plástico.

Procedimento 4: Deixe os experimentos sob iluminação natural por algum tempo.

Vale ressaltar, que essa experiência foi realizada anteriormente pelos pesquisadores, ficando os experimentos sob iluminação natural cerca de trinta e quatro minutos como verificação prévia da efetividade da proposta.

Após este momento, os estudantes foram conduzidos para a área externa do prédio e instruídos a deixar os experimentos sob a iluminação solar por um tempo aproximado de trinta e quatro minutos. Enquanto esse tempo transcorria os estudantes retornaram a sala de aula para estudarem o método hipotético dedutivo teoricamente.

Decorridos o período estabelecido de trinta e quatro minutos de exposição do experimento a iluminação solar, os estudantes foram convidados a retornar à área externa do prédio para pegarem os experimentos e trazê-los de volta a sala de aula para a devida 
Revista ta Rede Amazorinica de Edurecrăo
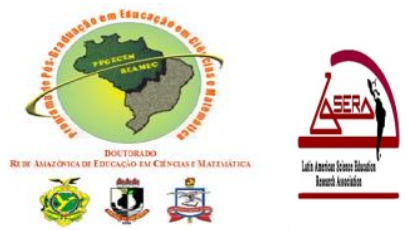

observação do processo após a exposição a luz solar. Para essa etapa foi então solicitado dos estudantes as seguintes atividades:

Procedimento Final: Observe o experimento (copo) olhando de cima. Observe também o saco plástico do pote.

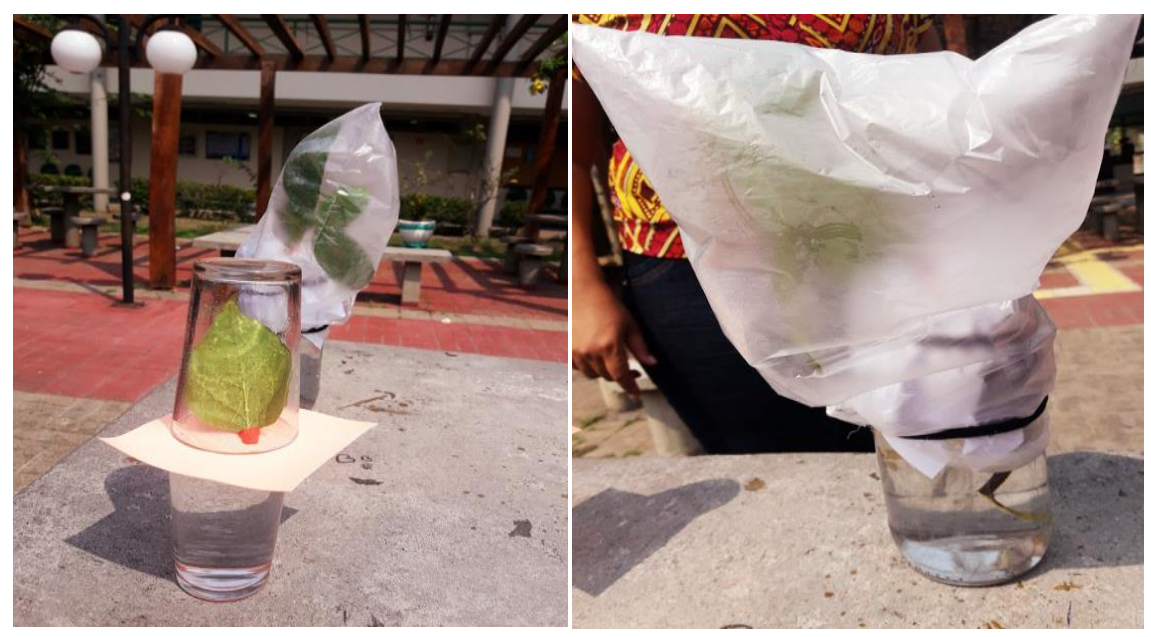

Figura 3: Experimento com o copo de vidro e experimento com saco plástico após exposição à luz solar Fonte: Autores

No momento da observação do experimento iniciamos a etapa do método hipotéticodedutivo denominada de falseamento, que consiste no teste da hipótese proposta. De acordo com Popper (1975), o falseamento pode ser feito, dentre outras formas, através de experimentação ou análise de estatísticas. Após analisados os resultados, são avaliadas as conjecturas, soluções ou hipóteses previamente elaboradas, que podem ser reputadas, rejeitadas ou corroboradas.

Neste momento, os estudantes iniciaram as atividades que o roteiro propunha baseados na observação do experimento. A primeira atividade do roteiro solicitava que os estudantes explicassem qual o fenômeno observado quando olharam o experimento após a exposição à iluminação solar? Dentre as afirmações que pontuaram tomamos como análise a resposta da estudante 1 que disse: "Dentro da folha ela já tem líquido, e devido ao sol ela evaporou, não por causa da respiração, mas foi evaporação do líquido que já tem na folha" (Estudante 1).

Com essa explicação da Estudante 1, observamos que a mesma tem a percepção de que houve uma evaporação do líquido contido na folha. Neste momento, realizamos uma intervenção a partir da fala da estudante explicando que o conteúdo da transpiração das 


\section{REVISTA REAMEC}

Revista ta Rede Amazorinica de Edurecrăo

em Ciêneias e Matemática

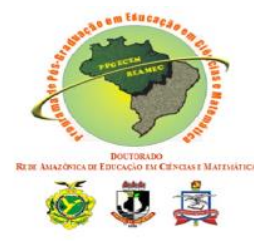

plantas está relacionado com o ciclo da água e com a fotossíntese. Para que ficasse mais claro que o processo que ocorreu não foi somente a evaporação, mas sim, a transpiração. Exemplificamos o experimento com uma planta que não é regada. Se uma planta transpira diariamente e a quantidade de água que a mesma perde não for adicionada, essa planta com certeza irá murchar e consequentemente morrer.

Outro questionamento que foi feito é se as gotículas (suor) sobre as folhas foram decorrentes da água que estava em contato com a folha ou da água contida na folha? A Estudante 1 respondeu que essas gotículas são decorrentes das duas formas. Isso demonstra que houve percepção do processo que ocorreu na folha, onde a folha sugou uma quantidade de água e essa água ficou em sua base e com a estrutura que manteve o experimento abafado, foi possível a visualização da transpiração.

No decorrer das atividades do roteiro ocorreu intensa discussão entre os estudantes resultante de novos questionamentos, como por exemplo, "sobre se a folha iria transpirar da mesma forma caso ela não estivesse em contato diretamente com água". Em meio a este questionamento, esclarecemos que esta dúvida que foi gerada poderia ser outra hipótese para posterior testagem, caso a hipótese inicial viesse ser refutada.

Outro questionamento da atividade foi sobre "qual a relação que os estudantes observaram no experimento com o ciclo da água?”. Em resposta a esta questão obteve-se a seguinte resposta da Estudante 2: "ela estava líquida e depois passou para o estado gasoso, ela evaporou". Então completamos a resposta da estudante afirmando que quando a água da planta estava no estado gasoso e devido ao experimento estar fechado, não tendo como a água evaporar pelo ar, então ela novamente volta do estado gasoso para o líquido, ficando suas gotículas expostas sobre a folha e sobre o material do experimento pelo lado interno.

Ao retirarmos os copos de cima dos experimentos sugerimos que estes passassem de mãos em mãos pelos estudantes para que estes tocassem, cheirassem e sentissem a temperatura das folhas, com isto foi possível a percepção da ação do sol sobre a folha, pois as folhas estavam aquecidas. Sendo assim, outras hipóteses foram surgindo de acordo com o que foi observado no processo, tais como: “as plantas só transpiram se houver calor" (Estudante 3), "as plantas têm cheiro" (Estudante 4). 


\section{REVISTA REAMEC}

Revista ta Rede Amazorinica de Edurecrăo

em Ciêneias e Matemática
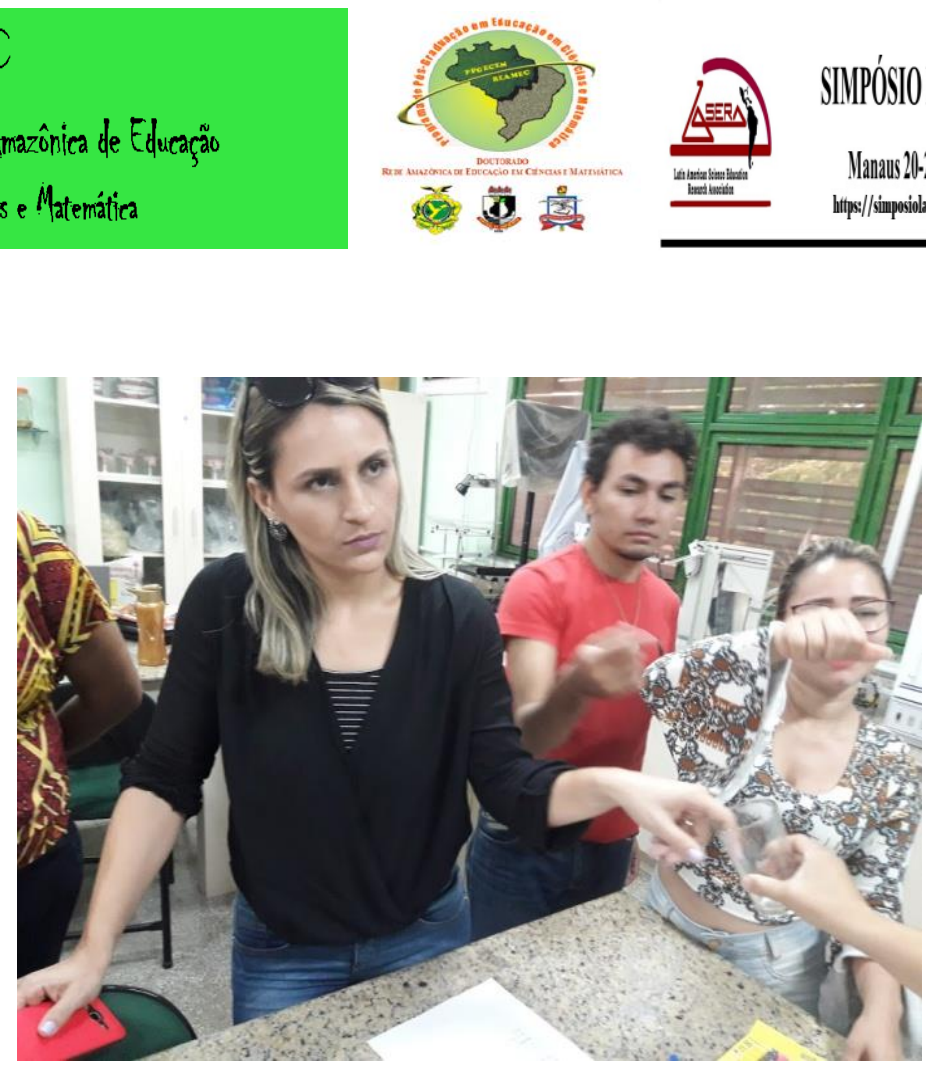

Figura 4: Estudantes realizando atividades do roteiro

Fonte: Autores

Observando as diferenças entre os três tipos de experimentos que foram elaborados percebemos a seguinte diferença entre eles: nos experimentos que foram cobertos com o copo plástico e com saco plástico, foi mais visível a presença da transpiração, já no experimento que foi coberto com copo de vidro, a visibilidade de transpiração foi menor, o que atesta que o tipo de material utilizado, sendo estes com maior ou menor capacidade de condução de calor, influencia na frequência e na quantidade de transpiração das plantas.

Para finalizar o experimento, voltamos à leitura das atividades propostas no roteiro para analisarmos a hipótese inicial que afirmava: "A transpiração dos vegetais é um processo que ocorre quando a planta absorve água”. Diante da hipótese levantada perguntamos aos estudantes se esta afirmação era verdadeira ou falsa, e por unanimidade, os estudantes responderam que era uma afirmação verdadeira, sendo então esta hipótese corroborada neste estudo.

Vale ressaltar, que ao realizar qualquer experimento utilizando o método hipotéticodedutivo, é fundamental realizar a leitura da hipótese tanto no inicio, como ao finalizar o experimento, visto que, todo o intuito investigativo será em função da hipótese em questão. 


\section{CONCLUSÃO}

Apesar de o método hipotético-dedutivo ser pouco utilizado em práticas educacionais no Ensino de Ciências, aulas com esta experimentação aponta a possibilidade de experimentos para este método. No entanto, é importante que o professor tenha uma compreensão ampla do método para que os direcionamentos do estudo não sofra interferências de outras metodologias e assim ocasionar confusão na compreensão acerca do método por parte dos estudantes.

A vantagem da experimentação com o método proposto está exatamente na tentativa de eliminação de erros, visto que, durante o processo é comum surgirem dúvidas, problemas e outras supostas hipóteses, o que faz com que ocorra a possibilidade de eliminação de hipóteses equivocadas, onde o professor é quem irá direcionar os estudantes à uma compreensão correta acerca do conhecimento científico desejado.

Desse modo, entende-se que o educador é o responsável em buscar instrumentos que possibilitem uma aprendizagem contextualizada com a vivência do aluno. O processo educativo depende na sua plenitude do ato de aprender. Contudo, é importante que para que esse aprender aconteça, seja necessário o uso de estratégias e recursos que estimulem o entendimento lógico científico. Perceber essa necessidade no processo educativo pode ser um referencial necessário na questão do aprendizado de conceitos.

Neste sentido, entende-se que a ciência faz parte do cotidiano do estudante e que o mesmo precisa não só questionar, mas refletir sobre seu próprio questionamento. Desta maneira, o ensino precisa ser uma prática planejada pedagogicamente. Todavia, se o educador percebe que seu trabalho com o ensino não está alcançando o estudante, pois o ato de ensinar pode não ser o mesmo ato de aprender do aluno, este educador deve então analisar que ferramentas poderiam ser utilizadas além das que já utiliza e quais poderiam ser modificadas num processo de repensar a prática buscando a efetividade nesse processo.

Diante dessa experiência, concluímos que o Método Hipotético Dedutivo se usado com planejamento e disposição por parte do professor, pode se tornar uma ferramenta útil para práticas educacionais no ensino de Ciências não só no Ensino Fundamental, mas em qualquer nível de escolaridade. 


\section{REVISTA REAMEC}

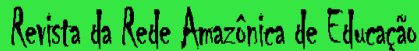

em Ciêneias e Matemática
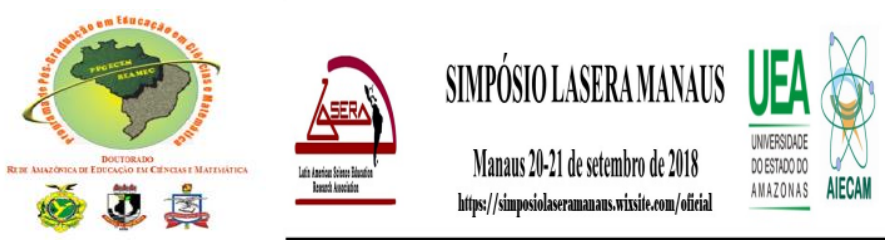

\section{REFERENCIAS}

BRASIL. Secretaria de Educação Fundamental. Parâmetros Curriculares Nacionais: Ciências Naturais. Brasília: MEC/SEF, 1998.

BUNGE, Mário. La ciencia, su método y su filosofia. Buenos Aires: SigloVeinte, 1974a. CHASSOT, Attico. Alfabetização Científica - Questões e Desafios para a Educação, Ijuí, Editora da Unijuí (6. ed. reimpressão 2014) 2000.

CONAN, C. A. História Ilustrada da Ciência (III). Rio de Janeiro: J. Zahar Editores, 1987.

MARCONI, M. de A.; LAKATOS, E. M. Metodologia científica. 5. Ed. 4. São Paulo: Atlas, 2003.

PONTES,

POPPER, Karl S. A lógica da pesquisa científica. 2. ed. São Paulo: Cultrix, 1975a. Conhecimento objetivo: uma abordagem evolucionária. São Paulo: Itatiaia: EDUSP

$1975 b$

Conjecturas e refutações. Brasília: Universidade de Brasília, s.d. 